\title{
Molecular Docking, Pharmacokinetic Properties and Toxicity Studies of Novel Folate Conjugated To a-Tocopherol via Peptide Bond
}

Shams H. Abdel-Hafez ( $\sim$ s.abdelhafez@tu.edu.sa )

Taif University

Adil A. Gobouri

Taif University

Anber. F. Mohammed

Assiut University

Mostafa A. Hussein

Albaha University

\section{Research Article}

Keywords: a-tocopherol, folic acid, molecular docking, pharmacokinetic properties, folate conjugated atocopherol(VAF)

Posted Date: April 9th, 2021

DOl: https://doi.org/10.21203/rs.3.rs-389569/v1

License: (9) This work is licensed under a Creative Commons Attribution 4.0 International License. Read Full License 


\section{Molecular Docking, Pharmacokinetic Properties and Toxicity Studies of Novel Folate Conjugated To $\alpha$-Tocopherol via Peptide Bond}

Shams H. Abdel-Hafez ${ }^{1 *}$, Adil A. Gobouri ${ }^{1}$, Anber. F. Mohammed ${ }^{2}$, Mostafa A. Hussein ${ }^{2,3}$

${ }^{1}$ Department of Chemistry, College of Science, Taif University, P.O. Box 11099, Taif 21974, Saudi Arabia

${ }^{2}$ Department of Pharmaceutical Organic Chemistry, Faculty of Pharmacy, Assiut University, Assiut 71526, Egypt

${ }^{3}$ Department of Pharmaceutical Chemistry, Faculty of Clinical Pharmacy, Albaha University, Albaha 1988, Saudi Arabia

\section{Abstract:}

A novel folate conjugated to $\alpha$-tocopherol (VAF) via peptide bond was Successfully synthesized by using three components vitamin e ( $\alpha$-tocopherol), chloro acetamide and folic acid under mild and simple conditions. The new synthesized compound was characterized by proton nuclear magnetic resonance ${ }^{1} \mathrm{H}$ NMR, ${ }^{13} \mathrm{H}$ NMR and Fourier transform infrared (FT-IR) analysis. A molecular docking study for targeted compound (VAF ) was performed and showed growth-inhibitory activity towards the human folate receptor alpha $(\mathrm{FR} \alpha)$ that may affectively the folate uptake by cancer cells. Further, The predicted pharmacokinetic properties and toxicity of the compound (VAF) and folic acid (F) were determined using a statistical analysis (ADMET). It was suggested that pharmacokinetic properties of compound (VAF) represents a promising drug and used as anticancer agents.

Keywords: $\alpha$-tocopherol; folic acid; molecular docking; pharmacokinetic properties; folate conjugated $\alpha$-tocopherol(VAF)

\footnotetext{
* Correspondence author : Department of Chemistry, College of Science, Taif University, P.O. Box 11099, Taif 21974, Saudi Arabia (e-mail: s.abdelhafez@tu.edu.sa; shams_abdelhafez@yahoo.com )
} 


\section{Introduction:}

Vitamin E (tocopherol and tocotrienols) [1] has antioxidant properties that subside unstable free radicals by supplying one of their electrons to the deficient free radical electron via a phenolic hydroxyl group (Fig. 1), allowing it more stable. [2]. Vitamin e (-tocopherol), which was chosen for research, controls vitamin A functions in the body and, in addition, protects the skin from harmful effects due to its anti-inflammatory properties [3].

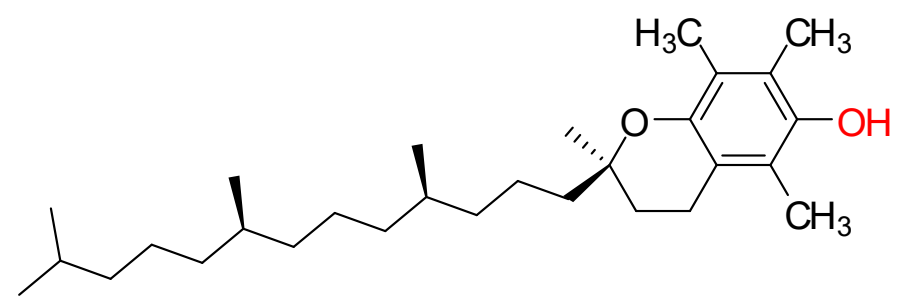

Fig 1: alpha-tocopherol structure

On the other hand, Folate is one of the B vitamins referred to as vitamin $\left(\mathrm{B}_{9}\right)$ or folic acid produced by the body that has been converted into folate $[2,3]$. Furthermore, folate is used by the body to produce DNA and RNA for cell division $[4,5]$ and is used as a supplement by pregnant women to avoid neural tube defects in their children [6-8]. Folate (Fig. 2) is based on three chemical moieties. A pterin is bound to p-aminobenzoyl group by a methylene bridge, which in turn is bonded to either glutamic acid or poly-glutamate by an amide linkage [9]. 


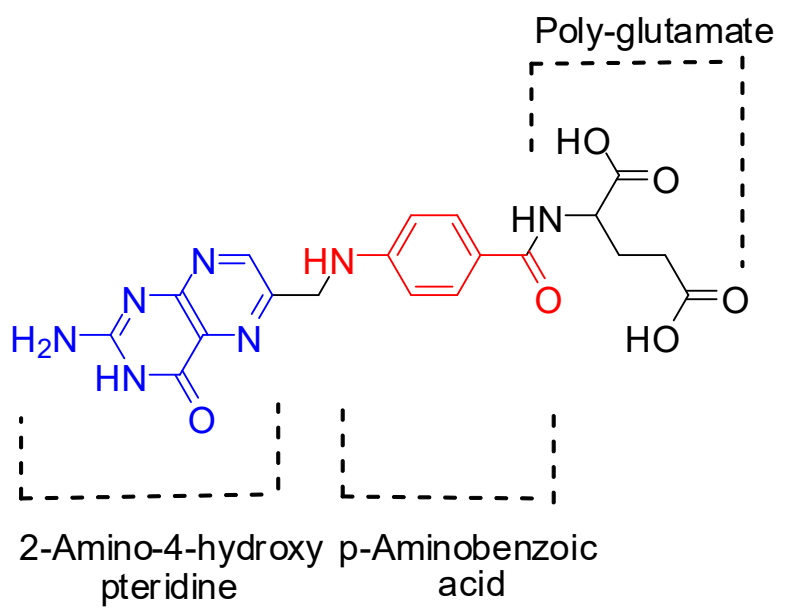

Fig 2: Folic acid (vitamin $B_{9}$ ) structure

According to a literature survey [10], using conjugated folic acid/cholesterol (CPF) to incorporate folic acid as a ligand in liposome systems allowed highly selective tumor-targeted liposome encapsulated doxorubicin with improved cytotoxicity within tumors. Several attempts to use folic acid as a targeting ligand conjugated to lipid or polymer with polyethylene glycol as a linker (Folate-PEG) have been made in the past [11-13].

In a previous paper [14], when vitamin e (-tocopherol) carrying selenated heterocyclic derivatives showed excellent cytotoxicity activity against human breast cancer cell line (MCF-7). Furthermore, Abdel-Hafez et al [15] developed a new class of vitamin e-containing sulfa drug derivatives, with the results showing a major effect on the antibacterial function of sulfa drugs linked to vitamin E. Based on previously reported results [10-14] for vitamin e as well as folic acid's biological activity effects, and in continuation of our attempts to synthesize new system based on vitamins linked together or linked to selenium or sulfur compounds $[14,15]$, the goal of this study was to synthesize and describe a biologically active folate linked with vitamin e ( $\alpha$ tocopherol) complex with human folate receptor $(\mathrm{FR} \alpha)$ in addition 
pharmacokinetic calculation hoping to access new classes of compounds, for cancer targeting.

\section{Results and discussion:}

\section{i) Chemistry}

Our question that how can linked together vitamin e with folic acid so, the starting compound folate conjugated vitamin e 4 (VAF) was designed and synthesized in two steps: initially, synthesis of $\alpha$-tocopherol acetamide derivative 2 (VA) by the reaction of $\alpha$-tocopherol $1(\mathbf{V})$ with chloroacetamide (A) as similar procedure with some modification [15] and as precursor material to synthesize the final target product 4 (VAF). The all resulted data was in agreements with reported literature [15]. The final step coupling reaction between derivative 2 (VA) and folic acid (3) afforded our target compound 4 (VAF). The conjugation reaction was carried out selectively, one of carboxyl group in folic acid and the amino group of another compound 2 (VA) where, water release to form targeting compound via peptide bond (Fig. 3). Chemical structure of the novel compound 4 was confirmed by both ${ }^{1} \mathrm{H}$ NMR and ${ }^{13} \mathrm{C}$ NMR in addition, FT-IR.

The IR spectrum revealed the appearance of new peptide bond group. ketone $\mathrm{C}=\mathrm{O}$ and amino group at 3318, $3126\left(\mathrm{NHNH}_{2}\right), 1697.9(\mathrm{C}=\mathrm{O})$ which indicated that folate conjugated to vitamin e. Also, ${ }^{1} \mathrm{H}$ NMR and ${ }^{13} \mathrm{C}$ NMR spectra supported our targeted compound 4 (VAF). 


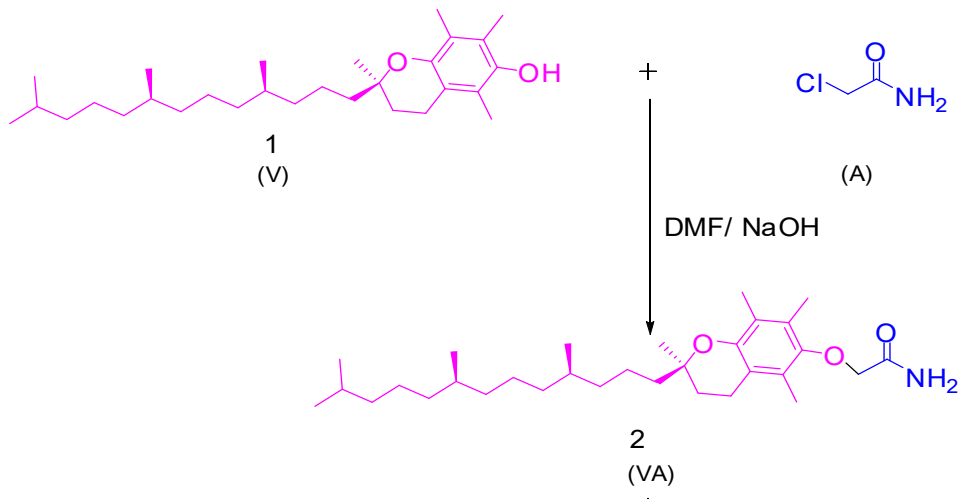

(VA)

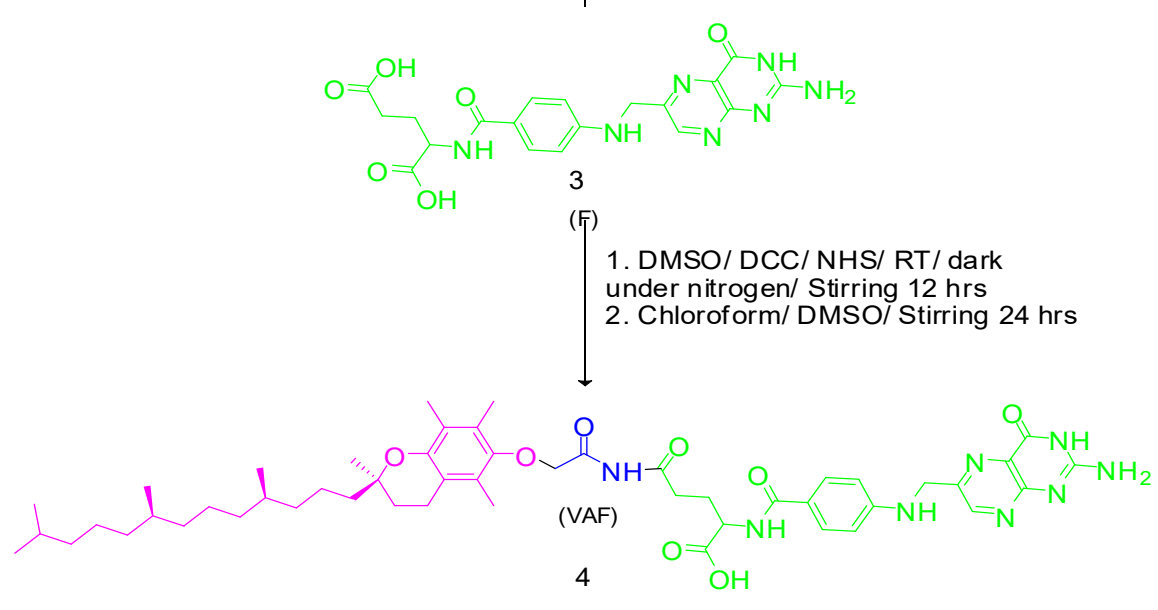

Fig.3:Schematic represenation synthesis of vitamin e - acetamide derivative (VA) followed by reaction with folic acid (VAF)

\section{ii) Molecular Modeling}

The crystal structure of human folate receptor $(\alpha-F R)$ in complex with folic acid (PDB: 4LRH) and (MOE) software [16] were used for modeling and docking the new folate conjugated $\alpha$-tocopherol compound. FR $\alpha$ is a folate receptor isoform overexpressed selectively in numerous tumors to mediate cellular uptake of folate under low folate conditions $[17,18]$. Results revealed that the new compound is docked deep inside the folate-binding pocket with a docking score $-9.4939 \mathrm{kcal} / \mathrm{mol}$, forming comparable interactions to those of folic acid with the surrounding amino acid residues (Fig 4B and 4D). The pteroate moiety is injected into the receptor, while the glutamate-conjugated - 
tocopherol moiety stays out of the pocket entry without disrupting the FR binding affinity. (Fig 4A and 4B). The pterin ring is capped by Tyr175 and stacked between the aromatic chains of Tyr85 and Trp171 forming $\pi$ - $\pi$ and $\pi$ $\mathrm{H}$ interactions with Tyr85 (3.66 and $3.79 \AA$ ) (Fig. 4A and 4C). Also, the hydrophilic pterin ring forms hydrogen bonds with the guanidinium group and indolyl moiety of Arg103 and Trp171, respectively (3.52 and 2.99 Å) (Fig. 4A and $4 \mathrm{C})$. The aminobenzoate moiety forms $\pi-\pi$ with Tyr 60 (3.66 $\AA$ ) and is fixed by hydrophobic interactions with Tyr60, Trp102 and Ser101, which contour the center of the long binding tunnel (Fig. 4A and 4C). Also, the glutamate group engages two hydrogen bonds with Lys19 and Lys136 (3.65 and $3.11 \AA$ ) along with $\mathrm{H}-\pi$ interaction with Trp140 (4.53 $\AA$ ). Other ligand interactions within the binding site are of hydrophobic type with Gln100, Trp171, Trp140, Lys136, His135, and Asn133.

As a potential anticancer agent targeting the folate receptor FR $\alpha$, the docking study provides insights into how the new folate conjugated $\alpha$-tocopherol compound extensively interacts with FR $\alpha$ with high binding affinity that may affect the folate uptake by cancer cells. 
A

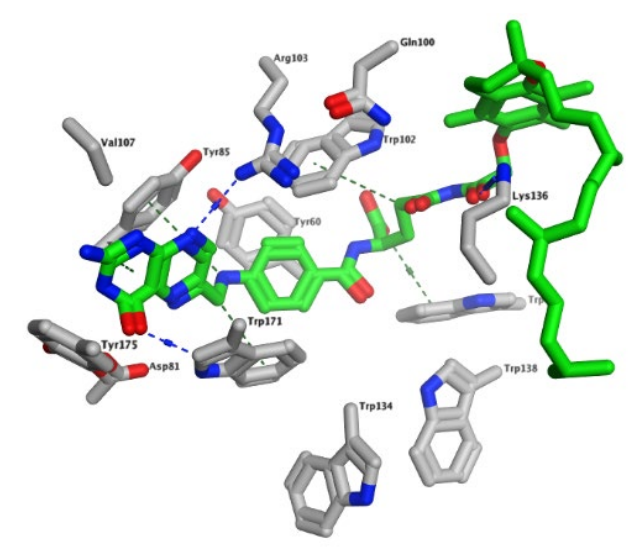

C

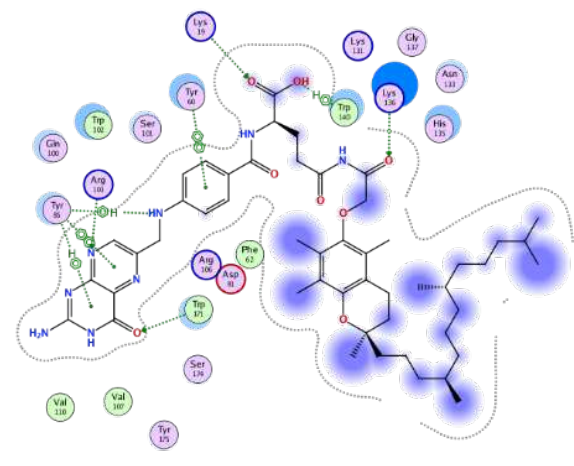

B

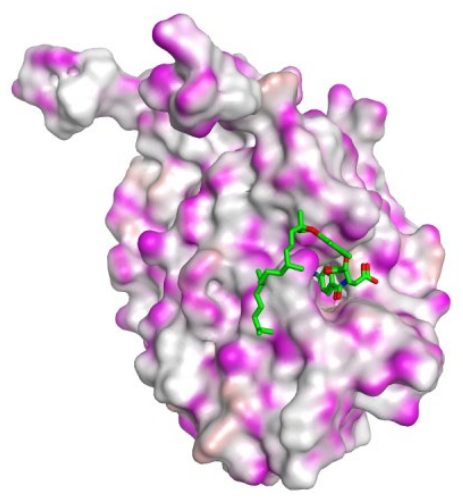

D

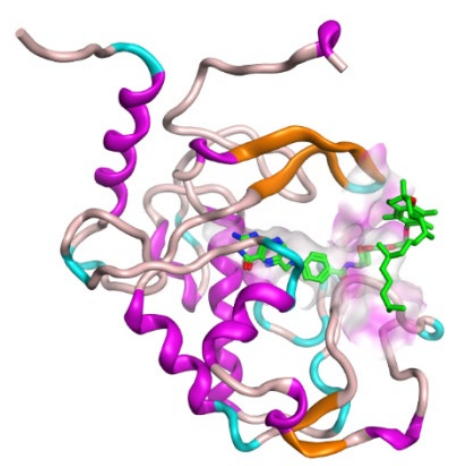

Figure 4: The model of the human FRa receptor in complex with the new folate conjugated $\alpha$-tocopherol compound: (A) $3 D$ model of the new ligand within the binding site of human FRa, (B) Surface of FRa with a close-up view of the ligand binding pocket entrance, (C) $2 D$ model of the new ligand within the binding site of human FRo, (D) Ribbon diagram of FRa with the new ligand showing semi-transparent binding surface. 


\section{iii) Pharmacokinetic}

Studies on absorption, distribution, metabolism, elimination, and toxicity [19]: A reliable methodology for predicting the toxicity and pharmacokinetic properties of the target compound and folic acid have been utilized and assessed by computer program and results were presented in Table 1. Studies on ADMET were predicted using pkCSM tool (http://biosig.unimelb.edu.au/pkcsm/prediction) [20]. Chemical structure of the tested compounds were subjected to conversion into SMILE molecular structures through a methodology using a PubChem (https://pubchem.ncbi.nlm.nih.gov) [19]. The screening was accepted as a methodological virtual way, relying on different parameters, since the target compound offered a strong Intestinal absorption (human percent) result of approximately 43.6 percent compared to 16.3 percent absorption of folic acid. Furthermore, the human colon adenocarcinoma-2 parameter (Caco2; high Caco2 permeability) [19] showed a positive outcome for the target compound(0.365) relative to folic acid(-1.076), implying that the target compound would show significant absorption when delivered orally[21], Table 1. As shown by steady-state volume of distribution (VDss), the target compound 4 (VAF) is predicted to have a lower theoretical dose needed for stable level of distribution in the plasma than folic acid itself, while the degree of crossing the plasma membrane barrier raised in this order: target compound folic acid, computed as the fraction that is in the free state. On the other hand, blood brain barrier transport of the target compound was considered as a minimum level since the observed data $(\log \mathrm{BB})$ were less than0.3, indicating that the compound can be used safely with limited side effects on the brain Table 1(No. 6). Moreover, the CYP isozymes are a group of enzymes that 
perform important roles in drug biotransformation. Table 1 (No. 7) indicates that the target compounds have a variable variety of CYP interactions. However, predicted in-silico toxicity was assessed because AMES toxicity testing revealed that none of the studied compounds had a mutagenic ability. In general, the target compound 4 (VAF) was found to be an effective hERG II inhibitor but not a hERG I; therefore, it could be linked to subsequent therapeutic cardiac effects [21]. Compound 4 (VAF) demonstrated adequate skin sensitization protection with the risk of inducing hepatotoxicity, as seen in Table 1. (No. 8). As an overall, the assessed pharmacokinetic parameters and toxicity of the final compound values confirmed that this compound possessed a promising pharmacokinetic properties in addition to good preferential EGFR inhibitory activities, and may be used as a lead compound in the development of promising, stable anticancer agents in the future.

Table 1: Pharmacokinetic properties and toxicity of compound 4 (VAF) and folic acid:

\begin{tabular}{|l|l|c|c|}
\hline No. & Model name (unit) & Folic acid & $\begin{array}{c}\text { Target compound } \\
4 \text { (VAF) }\end{array}$ \\
\hline 1 & Lipophilicity & -0.0448 & 8.04 \\
\hline 2 & Intestinal absorption (human\%) & 16.29 & 43.652 \\
\hline 3 & $\begin{array}{l}\text { Caco2 permeability (log Papp } \\
\text { in } 10-6 \mathrm{~cm} / \mathrm{s})\end{array}$ & -1.076 & 0.365 \\
\hline 4 & VDss- human (log L/kg) & -1.553 & -0.41 \\
\hline 5 & Fraction unbound- human & 0.349 & 0.116 \\
\hline 6 & BBB permeability (log BB) & -2.607 & -2.826 \\
\hline 7 & CYP2D6 substrate/ inhibitor & Yes & No \\
\hline 8 & CYP3A4 substrate/ inhibitor & No & Yes \\
\hline 9 & $\begin{array}{l}\text { AMES toxicity (Categorical: } \\
\text { Yes/No) }\end{array}$ & No & No \\
\hline 10 & hERG I inhibitor (Categorical: & No & No \\
\hline
\end{tabular}




\begin{tabular}{|l|l|c|c|}
\hline 11 & Yes/No) & $\begin{array}{l}\text { hERG II inhibitor (Categorical: } \\
\text { Yes/No) }\end{array}$ & No \\
\hline 12 & $\begin{array}{l}\text { Hepatotoxicity (Categorical: } \\
\text { Yes/No) }\end{array}$ & Yes & Yes \\
\hline 13 & $\begin{array}{l}\text { Sensitisation (Categorical: } \\
\text { Yes/No) }\end{array}$ & No & No \\
\hline
\end{tabular}

Caco2 stands for human colon adenocarcinoma-2, VDss stands for steady-state amount of distribution, and BBB stands for blood-brain barrier. AMES stands for Salmonella typhimurium reverse mutation assay, and hERG stands for human ether-a-go-go-related gene [19].

\section{Conclusion:}

A novel system of folate conjugated vitamin e was reported. A molecular docking study predicts highly activity towards the human folate receptor alpha $(\mathrm{FR} \alpha)$ and may uptake by cancer cells. Pharmacokinetic properties and toxicity of new hybrid compound (VAF) was calculated and predicated a promising drug can act as anticancer agent.

\section{Acknowledgement:}

Taif University supporting project number (TURSP-2020/23), Taif University, Taif, Saudi Arabia.

Also, author thanks Dr. Nebojsa Simic, Norwegian University of Science and Technology (NTNU) for working in his lab as a visiting professor, purchased chemicals and started primary prepared of our target compound (VAF). 


\section{Experimental}

\section{i- $\quad$ Chemistry}

Norwegian University of Science and Technology (NTNU) purchased vitamin E (alpha tocopherol), dicyclohexyl carbodiimide (DCC), n-hydroxy succinamide (NHS), chloroacetamide, and folic acid from Sigma-Aldrich. Using a Kofler melting point apparatus, melting points were determined. At Taif University Fourier transform infrared (FT-IR) analysis $\left(\mathrm{KBr}, \mathrm{cm}^{-1}\right)$ was measured on a Pye-Unicam SP3-100 instrument. Proton NMR spectra were recorded in ppm using TMS as a reference at King Abdel-Aziz University using a Varian (400 MHz) EM 390 USA instrument. ${ }^{13} \mathrm{C}$ NMR spectra were recorded on a JNM - LA spectrometer $(100 \mathrm{MHz})$. At the National Research Centre in Cairo, Egypt, mass spectra were measured using a JEOL-JMS-AX 500 .

Synthesis of 2-(4-((2-amino-4-oxo-3,4-dihydropteridin-6-yl)methylamino) benzamido)-5-oxo-5-(2-((R)-2,5,7,8-tetramethyl-2-((4R,8R)-4,8,12-trimethyltridecyl)chroman-6-yloxy)acetamide)petanoic acid (4)

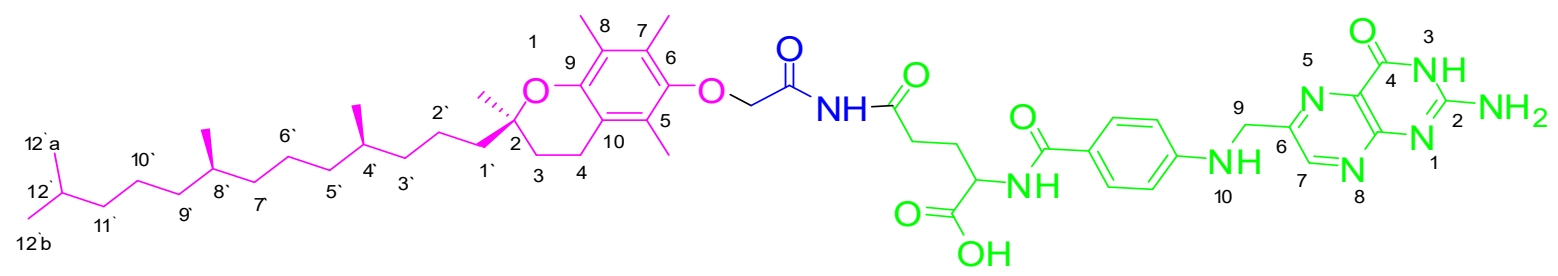

Folic acid was conjugated with vitamin $\mathrm{E}$ in two steps. In the first step, vitamin e 1 (V) conjugated with chloroacetamide (A) to form vitamin e amino 
derivative 2 (VA) as the same previously reported procedure with some modifications [Abdel-Hafez et al] [15]: to the mixture of alfa-tochopherol derivative $1(0.43 \mathrm{~g}, 1 \mathrm{mmol})$ in ethanol $(20 \mathrm{~mL})$, chloroacetamide derivative A $(0.093 \mathrm{~g}, 1 \mathrm{mmol})$ followed by $\mathrm{NaOH}(0.04 \mathrm{~g}, 1 \mathrm{mmol})$ were added. The reaction mixture was stirred at room temperature for $48 \mathrm{hrs}$., then added a mixtures of ethyl acetate $(30 \mathrm{~mL})$ and brine $(10 \mathrm{~mL})$ the aqueous layer was extracted with ethyl acetate ( $15 \mathrm{~mL}$ x 2$)$, the combined ethyl acetate extract was washed with brine (10 mL x 2), $\mathrm{H}_{2} \mathrm{O}\left(10 \mathrm{~mL}\right.$ x 1), dried over $\mathrm{MgSO}_{4}$. Ethyl acetate was evaporated and formed vitamin e/ amino derivative 2 (VA) which used to the next step directly. The all data was agreements with previously reported literature [15].

The second step includes conjugation of folic acid derivative 3 (F) with vitamin e/ amino derivative 2 (VA) as follows:

To the mixture of folic acid $3(0.44 \mathrm{~g}, 1 \mathrm{mmol})$ dissolved in DMSO $(10 \mathrm{~mL})$, a mixture of (DCC) dicyclohexyl carbodiimide $(0.21 \mathrm{~g}, 1 \mathrm{mmol})$ and (NHS) nhydroxy succinamide $(0.12 \mathrm{~g}, 1 \mathrm{mmol})$ were added. In dark under nitrogen atmosphere, at room temperature the reaction mixture was stirred for $12 \mathrm{hrs.,}$. After that [vitamin e / amino derivative $2(0.48 \mathrm{~g}, 1 \mathrm{mmol})$, dissolved in $\mathrm{CHCl}_{3}$ $(10 \mathrm{~mL})$ and diluted with DMSO $(5 \mathrm{~mL})]$ was added and stirred for another 24 hrs., then, $\mathrm{CHCl}_{3}$ was evaporated on rotatory evaporator (under vacuum) and DMSO was removed by extracting with ether then, ether was evaporated to obtain our target product 4 (VAF) dried and recrystallized from $\mathrm{DMSO} / \mathrm{H}_{2} \mathrm{O}$ as faint brown crystals; yield $0.55 \mathrm{~g}(60 \%) ; \mathrm{mp}>300{ }^{\circ} \mathrm{C}$. IR (KBr) $v \max 3318$, $3126\left(\mathrm{NH}_{2}\right), 1697.9$ (ketone group) $\mathrm{cm}^{-1}$. Proton-NMR (DMSO-d 6,400 MHz): $\delta=12.50(1 \mathrm{H}$, br., $\mathrm{COOH}) ; 11.55,10.50(2 \mathrm{H}, \mathrm{s}, \underline{\mathrm{NH}}$-benzamide, $\underline{\mathrm{NH}}-$ peptide bond); 8.65 (1H, s, 7-pteridine moiety); 7.64-8.13 (3H, m, Ar-ring); 
$6.95\left(3 \mathrm{H}, \mathrm{s}, 2-\mathrm{NH}_{2}, 3-\mathrm{NH}-\right.$ pteridine moiety, $5.57(1 \mathrm{H}, \mathrm{s}, \mathrm{NH}-\underline{\mathrm{CH}}-\mathrm{COOH})$, 4.50, $4.70\left(6 \mathrm{H}, \mathrm{m}, \mathrm{CH}_{2}\right) ; 4.48\left(2 \mathrm{H}, \mathrm{s},-\mathrm{OCH}_{2}\right), 2.18\left(3 \mathrm{H}, \mathrm{s}, \mathrm{CH}_{3}, 2 \mathrm{CH}_{3}\right), 2.89$ $\left(3 \mathrm{H}, \mathrm{s}, \mathrm{CH}_{3}, 5-\mathrm{CH}_{3}\right), 1.72\left(3 \mathrm{H}, \mathrm{m}, 3 \mathrm{CH}, 4^{\prime}-\mathrm{H}, 8^{\prime}-\mathrm{H}, 12^{\prime}-\mathrm{H}\right), 1.62(6 \mathrm{H}, \mathrm{m}$, $\left.2 \mathrm{CH}_{3}, \quad 7-\mathrm{CH}_{3}, 8-\mathrm{CH}_{3}\right), \quad 1.52 \quad\left(24 \mathrm{H}, \quad \mathrm{m}, \quad 11 \mathrm{CH}_{2}, \quad 3-\mathrm{H}, \quad 4-\mathrm{H}\right.$, $\mathrm{H}\left(1^{\prime}, 2^{\prime}, 3^{\prime}, 5^{\prime}, 6^{\prime}, 7^{\prime}, 9^{\prime}, 10^{\prime}, 11^{\prime}\right), 1.02\left(12 \mathrm{H}, \mathrm{m}, 4 \mathrm{CH}_{3}, 4^{\prime}-\mathrm{CH}_{3}, 8^{\prime}-\mathrm{CH}_{3}, 12 \mathrm{a}^{\prime}-\mathrm{CH}_{3}\right.$, $\left.12 \mathrm{~b}^{\prime}-\mathrm{CH}_{3}\right) ;{ }^{13} \mathrm{C}$ NMR (DMSO-d $\left.6,100 \mathrm{MHz}\right): \delta=24.9\left(\mathrm{CH}_{3}, \mathrm{C} 2\right), 25.6$ $\left(\mathrm{CH}_{3}, \mathrm{C} 7\right), 25.7\left(\mathrm{CH}_{3}, \mathrm{C} 8\right), 25.9$ (C, C12'b), 26.5 (C, C12'a), 26.4, $28.4(\mathrm{C}$, $\mathrm{C}, 3,4), 28.6\left(\mathrm{CH}_{2}, \mathrm{C} 10^{\prime}\right), 29.6\left(\mathrm{CH}_{3}, \mathrm{C} 5\right), 29.8,30.4,30.7$ (C, $\left.\mathrm{C}^{\prime}, 8^{\prime}, 11^{\prime}\right)$, 31.9, 32.9 (C, C12'a), 33.7, 31.2 (C, C8), 33.4 (C,C12'), 35.7,36.3, 36.4, 37.4, 38.4, 39.3, $40.0\left(\mathrm{C}, \mathrm{Cl}^{\prime}, 2^{\prime}, 3^{\prime}, 5^{\prime}, 6^{\prime}, 9^{\prime}\right), 47.4,52.6,70.0\left(\mathrm{CH}_{2}, \mathrm{OCH}_{2}\right), 74.8(\mathrm{C}, \mathrm{C} 2)$, 112.6, 117.6 (C, C9), 122.6, 124.0 (C, C7'), 126.6 (C,C4'), 128.4, 129.1 ,129.3 (C, C7,8), 130.6, 157.1, 154.9, 152.7, 150.0, 147.5, 147.8 (C, C6), 148.2 (C,C10), 166.6, 167.5, 170.1, 173.2, 174.4 (C, CO). MS m/z (\%): $911\left[\mathrm{M}^{+}+1\right.$ $, 10)$.

\section{ii- $\quad$ Molecular Modeling}

Both molecular modeling calculations and docking simulation study were carried out using Molecular Operating Environment (MOE 2019.0102, 2020; Chemical Computing Group, Canada) as the computational software on a Processor Intel(R) Pentium(R) CPU N3510@1.99GHz and 4 GB Memory with Microsoft Windows 8.1 pro (64 Bit) operating system. All MOE minimizations were carried out until the force field (Amber10: EHT) and a RMSD gradient of $0.01 \mathrm{Kcal} / \mathrm{mol} / \AA$ to calculate the partial charges automatically using a reaction field solvation. The protein was protonated with the LigX function and the ligand was isolated before simulations. The top 30 poses were optimized using force field (Amber10: ETH) and 
GBVI/WSA $d G$ scoring after the triangle matcher with London $\mathrm{dG}$ scoring was selected for initial placement. The final score feature was used to build the output database dock file, which included separate poses for each ligand (S), which is the score of the last stage that was not set to zero. Top pose from this simulation was analyzed and compared to the binding site of the reference drug folic acid.

\section{iii- Pharmacokinetics}

\section{ADMET studies:}

Computer aided evaluation for assessment of pharmacokinetic parameters and toxicity of the target compound and folic acid have been carried out depending on their ADMET profiles and results were listed in Table 1. ADMET evaluation were assessed by pkCSM device (http://biosig.unimelb.edu.au/pkcsm/prediction) [19]. Molecular structures in the SMILE forms of the compounds were handled from PubChem (htt ps://pubchem.ncbi.nlm.nih.gov) [19].

\section{References:}

[1] Machlin, L. J. Handbook of Vitamins, 3rd ed.; New York: Marcel

Dekker, 1991; pp. 99-144.

[2] Chen, G. R.; Praly, J. P. C. R. Chim. 2008, 11, 19-28.

[3] Reberto Cassano, (January 2012). In book: Handbook of diet, nutrition and the skin. 
[4] Micronutrient Information Center, Linus Pauling Institute, Oregon State University. 2014. Retrieved 17 March 2018.

[5] Drugs.com. American Society of Health-System Pharmacists. 1 January 2010. Archived from the original on 8 August 2017. Retrieved 1 September 2016.

[6] Fact Sheet for Health Professionals - Folate". National Institutes of Health. Archived from the original on 2 April 2011.

[7] West AA, Caudill MA, Bailey LB (2020). "Folate". In BP Marriott, DF Birt, VA Stallings, AA Yates (eds.). Present Knowledge in Nutrition, Eleventh Edition. London, United Kingdom: Academic Press (Elsevier). pp. 273-88. ISBN 978-0-323-66162-1.

[8] Bibbins-Domingo K, Grossman DC, Curry SJ, Davidson KW, Epling JW, García FA, et al. (January 2017), JAMA. 317 (2): 183 189.

[9] Zheng Y, Cantley LC (February 2019), The Journal of Experimental Medicine. 216 (2): 253-266.

[10] Atul A. Lohade, Rajesh R. Jain, Krishna Iyer, Sushant K. Roy, Hemant H. Shimpi, Yogita Pawar, M. G. R. Rajan, and Mala D. Menon, AAPS Pharm. Sci. Tech., (2015)

[11] Gao W, Xiang B, Meng T-T, Liu F, Qi X-R., Biomaterials, 2013; 34 (16), 4137-49.

[12] Xiang G, Wu J, Lu Y, Liu Z, Lee RJ. J Pharm. 2008, 356 (1):2936.

[13]Yang C, Chen H, Zhao J, Pang X, Xi Y, Zhai G. Colloids Surf B: Biointerfaces, 2014;121:206-13..

[14] Shams H. Abdel-Hafez, Ahmed B. Abdelwahab, and Gilbert Kirsch. Design, synthesis and cytotoxic activity of vitamin E bearing 
selenium compounds against human breast cancer cell line (MCF-7)

[15] Abdel-Hafez, H. Sh., Gobouri, A. A., Alshanbari, N. A.,

Gad El-Rab, S. M. F., Medicinal Chemistry Research (2018) 27, 23412352.

[16] Molecular Operating Environment (MOE), 2019.01; Chemical

Computing Group ULC, 1010 Sherbooke St. West, Suite \#910, Montreal, QC, Canada, H3A 2R7, 2020.

[17] Chen, C. et al. Structural basis for molecular recognition of folic acid by folate receptors. Nature 500, 486-489 (2013).

[18] Kelemen, L. E. International Journal of Cancer, 2006, vol. 119, 243-250

[19] Noha H. Amin, Mohammed T. Elsaadi, Shimaa S. Zaki, Hamdy M. Abdel-Rahman. "Design, synthesis and molecular modeling studies of 2styrylquinazoline derivatives as EGFR inhibitors and apoptosis inducers", Bioorganic Chemistry, 105, 2020, 104358

[20] Pires, D.E.V., Blundell, T.L., Ascher, D.B. pkCSM, J. Med. Chem. 58 (9) (2015) 4066-4072,

[21] Adeoye, A.O., Oso, B.J., Olaoye, I.F., Tijjani, H., Adebayo, A.I., J. Biomol. Struct. Dyn. (2020). 
Figures

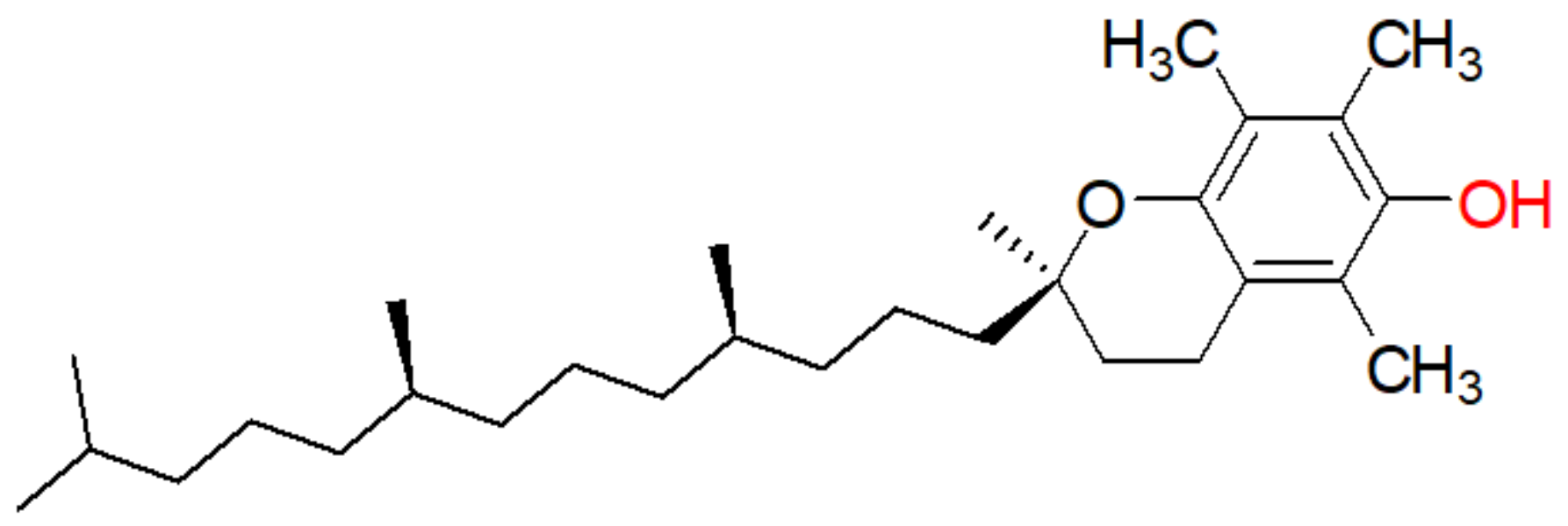

Figure 1

alpha-tocopherol structure

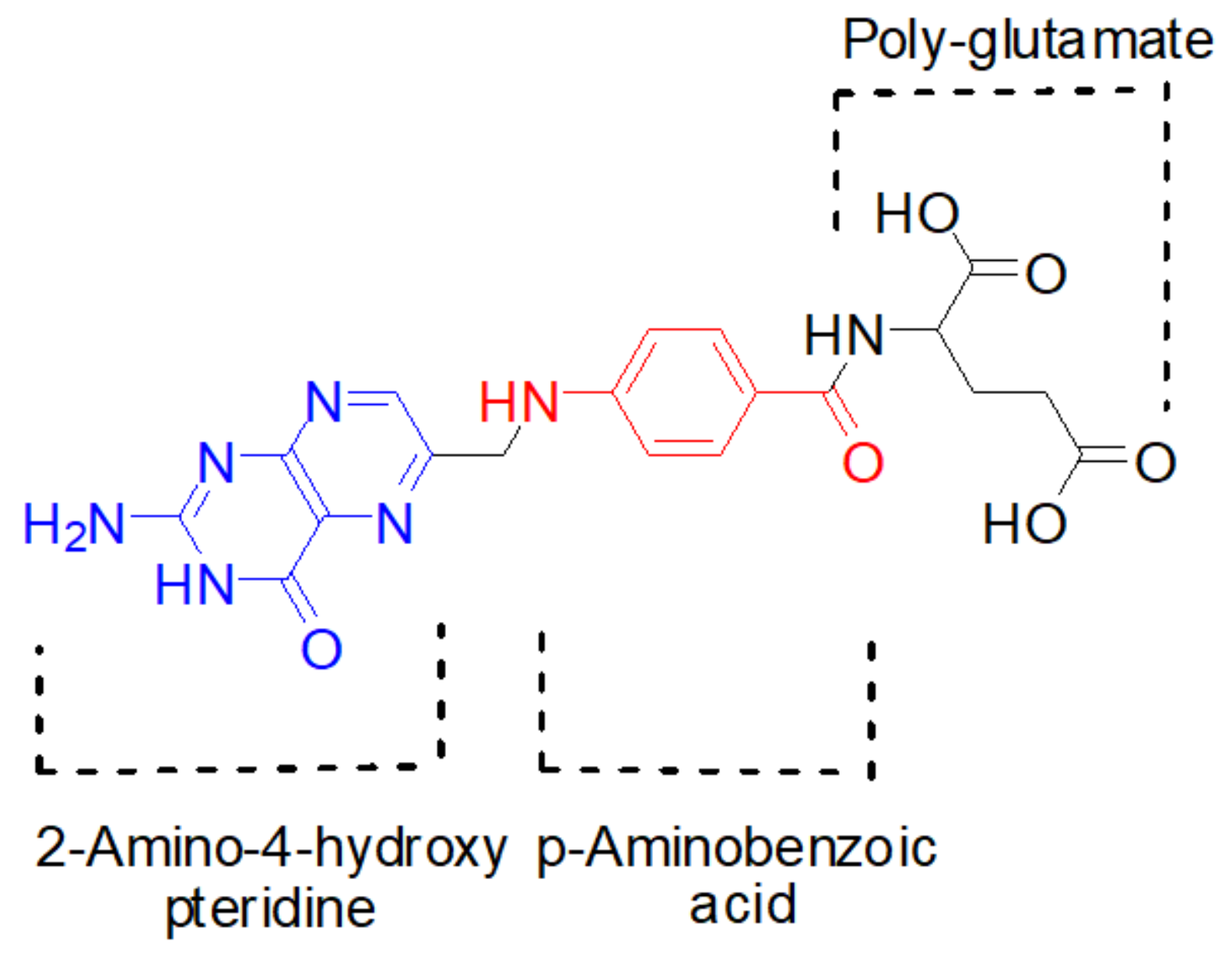

Figure 2 
Folic acid (vitamin B9) structure
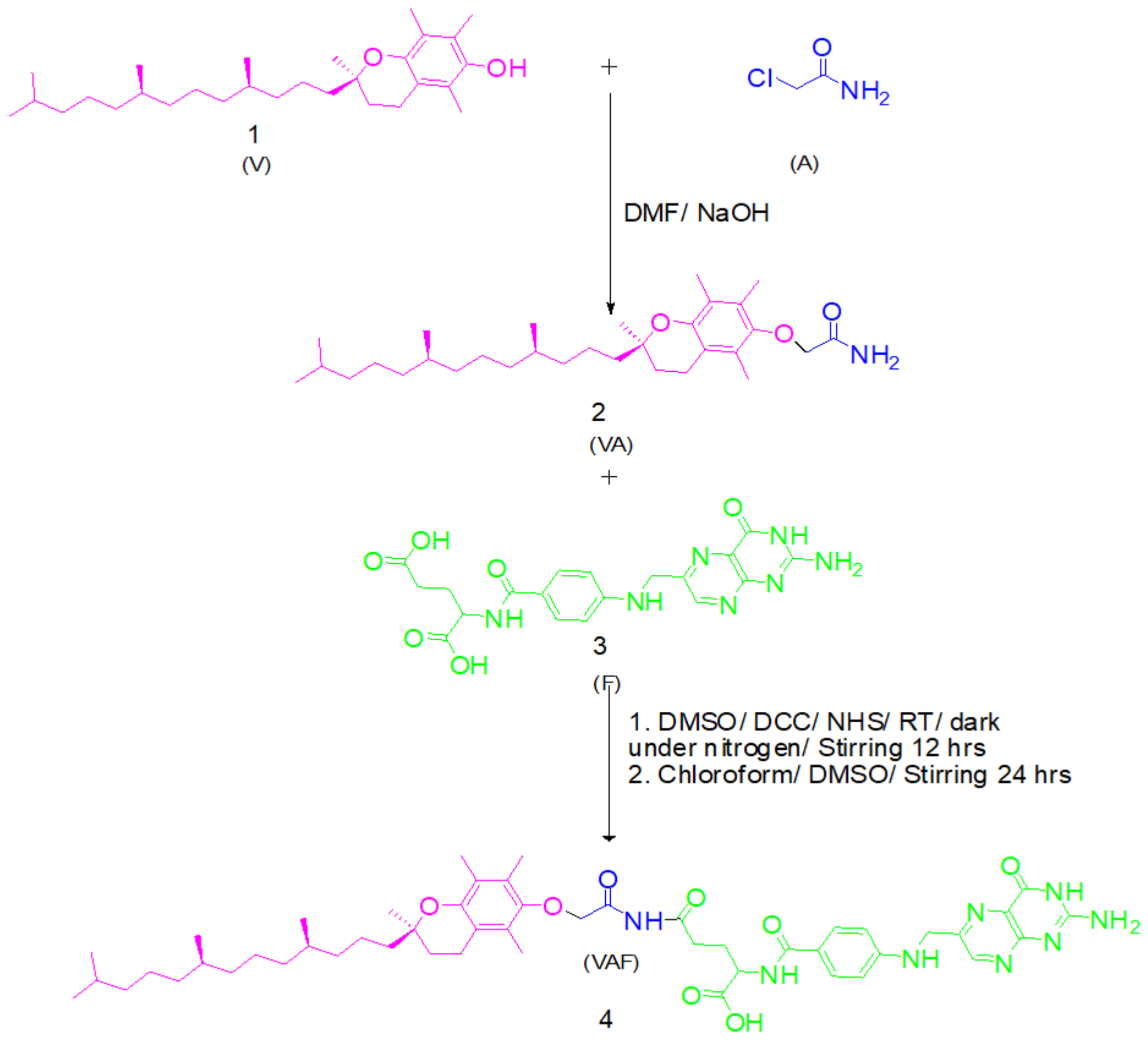

Figure 3

Schematic representation synthesis of vitamin e-acetamide derivative (VA) followed by reaction with folic acid (VAF) 
A

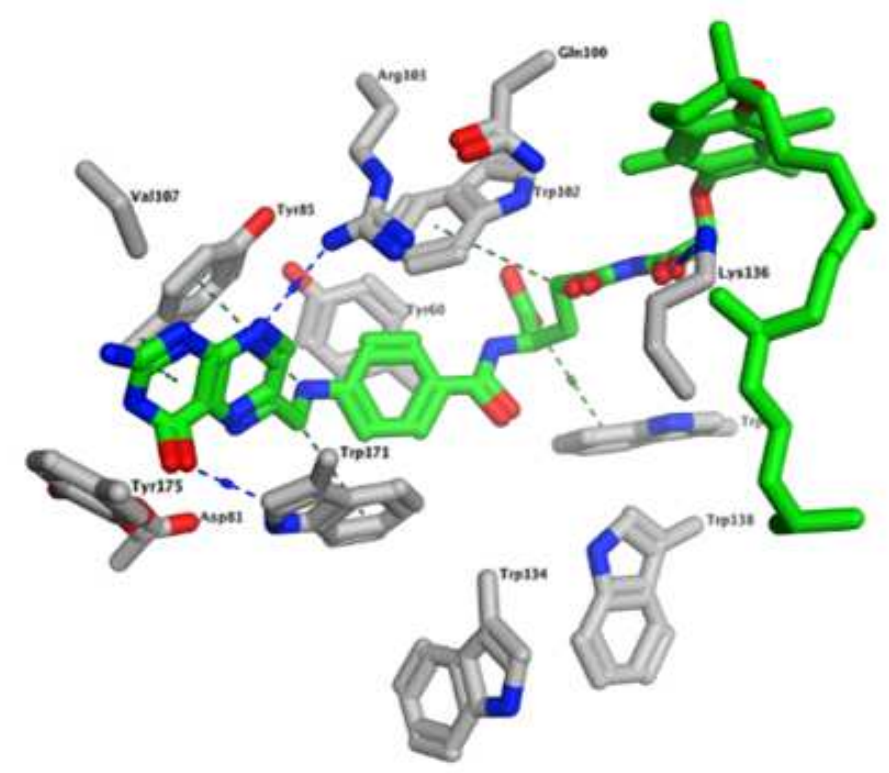

C

(i)

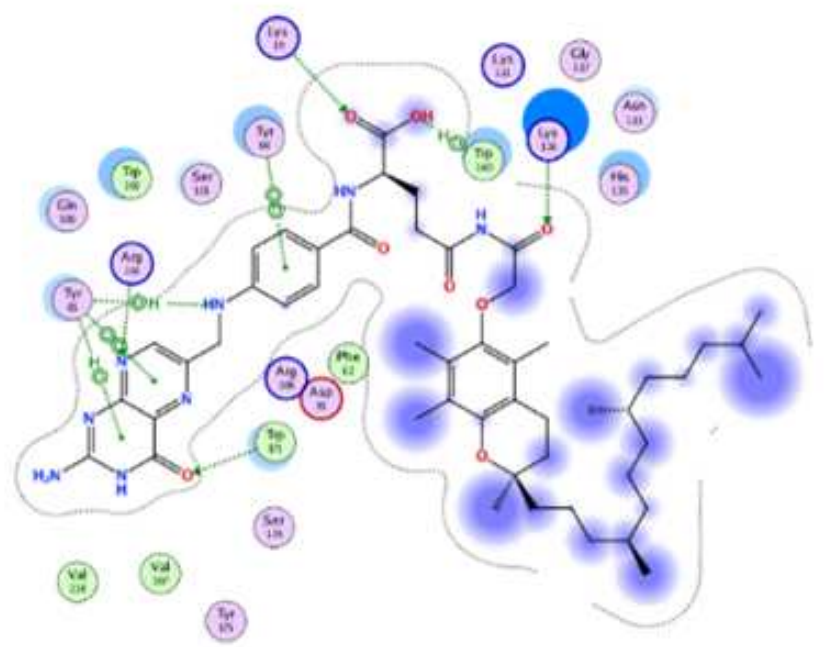

B

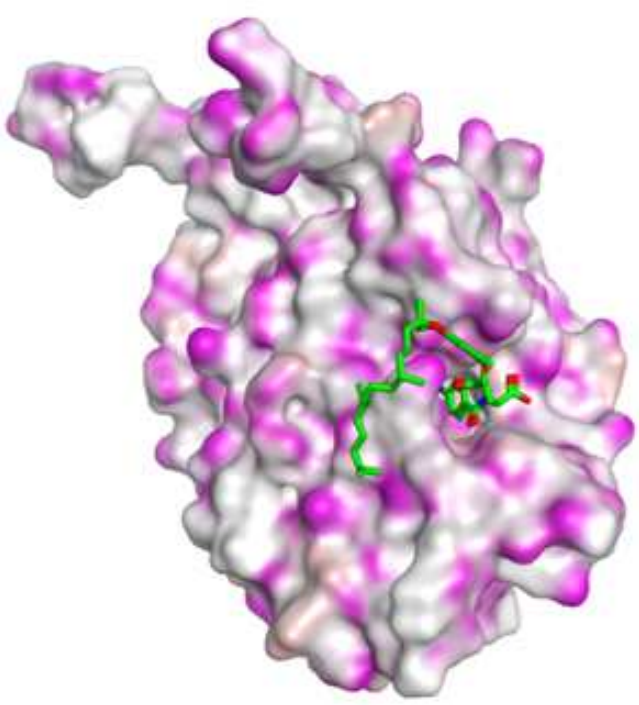

D

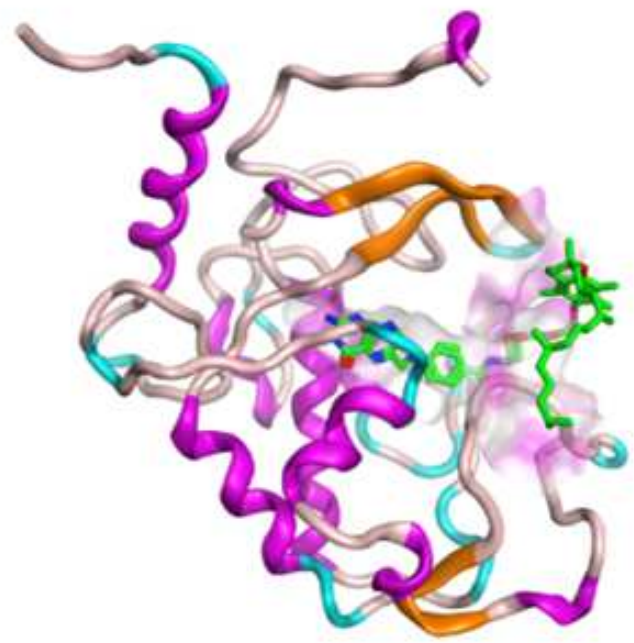

\section{Figure 4}

The model of the human FRa receptor in complex with the new folate conjugated a-tocopherol compound: (A)3D model of the new ligand within the binding site of human FRa, (B) Surface of FRa with a close-up view of the ligand binding pocket entrance, (C) $2 \mathrm{D}$ model of the new ligand within the binding site of human FRa, (D) Ribbon diagram of FRa with the new ligand showing semi-transparent binding surface. 